\title{
“Teen Views of Sex:" Inter-animation of dialogues in a radio feature story produced by Mexican immigrant youth
}

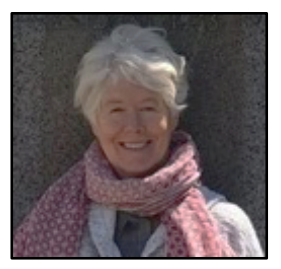

Dana Walker

University of Northern Colorado, US

\begin{abstract}
This paper proposes an analysis of dialogical processes in the creation of a radio feature story titled "Teen Views of Sex," co-produced by Mexican immigrant high school students in the context of a Youth Radio and Radio Arts program. After describing the socio-cultural and curricular context of the program, I apply Zittoun and Grossen's (2013) semiotic approach to dialogicality to describe the kinds of dialogue that took place during the interviews and subsequent reflections upon the feature story and production process. The types of dialogue examined include: actual dialogue, distant dialogue, auto-dialogue, dialogue between situations, and dialogue with material objects, or non-human actants. I explore how the inter-animation of these forms of dialogue gave rise to dialogic tensions, which may have created openings for shifts in identity positioning and an enhanced sense of agency for the youth in their personal and public lives.
\end{abstract}

Dana Walker is professor of Culturally and Linguistically Diverse Education at the University of Northern Colorado. Her research focuses on youth media, poetry, and arts for multilingual youth, most recently in a Translocal Youth Media research project that connects students and teachers in Barcelona and Greeley, co.

$\cos \cos 80$

\section{Introduction}

Advances in dialogical pedagogy in the past several decades have provided a hopeful counter narrative to the generally dehumanizing approach to education in the United States, which privileges testing over inquiry, de-professionalizes teachers through the imposition of recitation scripts, and provides inequitable learning opportunities for the children of working class immigrant families. In educational research, empirical studies have moved the field forward in helping us understand the potential benefits of dialogic practice as well as the challenges it poses (e.g., Resnick, Asterhan, \& Clarke, 2015). However, educational researchers tend to limit themselves to dialogue that is visible and measurable, which "misses the most important thing which is the invisible opening of dialogic space" (Wegerif, 2017) within which participating voices enter into a relationship of "inter-illumination," where the persuasive words of others enter into one's own (Bakhtin, 1981). These invisible openings are worthy of consideration because they may also represent potential openings for the self-authoring or the "reinvention of self" (Zittoun, 2014) along

\footnotetext{
${ }^{1}$ This research was conducted with support from a Spencer Foundation Small Grant.
} 
with shifts in cultural practices when individuals introduce novelty in their externalizations in ways that can potentially transform meanings and practices (Freire, 2005; Skinner, Valsiner, \& Holland, 2001).

In this article I propose an analysis of dialogical processes that emerged in the creation of a radio feature story titled "Teen Views of Sex," co-produced by Tania and Yoli in the context of a Youth Radio and Radio Arts program for first and second generation immigrant youth. ${ }^{2}$ I draw on Zittoun and Grossen's (2013) model, which provides the analytical tools for examining the different types of dialogue involved in students' use of cultural elements (philosophy or history texts) to construct a continuity of self across multiple spheres of experience. In the analysis presented here, I describe the kinds of dialogue that took place between Tania, Yoli, their interviewees and myself, in the planning, implementation, and postproduction of the radio feature story. I explore how the inter-animation of these varieties of dialogue set in motion through the creation of the feature story, gave rise to dialogic tensions that may have played a role in developing greater self-consciousness, re-positioning in their social and semiotic fields, openings to new understandings and potential action in future.

\section{Situating this analysis of dialogical processes}

I situate my discussion in this paper within two broad areas of scholarship on dialogicality and dialogical pedagogy: 1) sociocultural psychology, specifically research that explores the dialogical processes through which the person may reinvent herself and contribute to collective change, together with the conditions that support or inhibit these processes (Skinner et al., 2001; Zittoun, 2014); and 2) scholars who explore dialogic pedagogy as a means for promoting student and teacher agency, democratic participation, and broad educational and social change (Freire, 2005; Matusov, Smith, Soslau, MarjanovicShane, \& von Duyke, 2016; Segal, Pollak, \& Lefstein, 2017). I am interested in the potential of dialogicality for opening spaces for self-authorship, in which the person may reinvent herself and re-envision herself as a powerful individual who is capable of transforming her social reality in collaboration with others, what Freire calls "dialogic action" (Freire, 2000/1970).

As noted above, whereas educational researchers of dialogical pedagogy tend to limit themselves to analyses of spoken dialogue in the classroom, recent research in cultural psychology has shown that dialogue, in fact, involves varied and heterogeneous processes, and is much more than the specific dialogue with internalized words of others, which is a common understanding of Bakhtin's (1981) notion of dialogism (Grossen \& Orvig, 2011; Marková, Linell, Grossen, \& Salazar Orvig, 2007; Valsiner, 2007b; Zittoun \& Grossen, 2013). From a dialogical perspective, dialogue can involve any reference to another time, situation, meaning, discourse, person, facets of self, or cultural object which creates the possibility of two perspectives to be held simultaneously in the mind. For example, the present and the past or future, here and over there, this situation and that situation, I and others, and so on, all located within in specific social settings shaped by wider political and ideological forces (Märtsin, Wagoner, Aveling, Kadianaki, \& Whittaker, 2011; Zittoun, 2014). Dialogical approaches have revealed the dynamic dimensions of self, freed from the limitations of a static and essentialized views (Grossen \& Orvig, 2011; Hermans \& Gieser, 2014; Ligorio \& César, 2013). Yet, how does one make sense of oneself and the world when one is subject to the inchoate flow of images, voices, contradictory narratives, identities, and expectations for behavior, especially during adolescence (Zittoun \& Grossen, 2013)? Holland and co-authors (Holland, Lachicotte, Skinner, \& Cain, 1998) use case studies to illustrate how self-authoring occurs when people use culturallydefined narratives and songs to "orchestrate" the voices of others. In the process, they inject their own intentions and perspective from their particular social position, as they engage and answer people who are

\footnotetext{
${ }^{2}$ Pseudonyms are used for all participants except for the professional mentors, who chose to have their real names used. Tania and Yoli were 15 years old at the time of this study.
} 
actually present or who may be far removed in time and space (Skinner et al., 2001). Zittoun and colleagues (Zittoun, 2006; Zittoun, Duveen, Gillespie, Ivinson, \& Psaltis, 2003) have argued that a cultural element, such as a novel or a history narrative, can play an important role in the emergence of agency, when the cultural element becomes a symbolic resource that supports psycho-social processes that link various spheres of experience: past and present, distant and near, fictional and real; school, life, and work. As a symbolic resource, a novel, for example, can serve as a model for responding to the multiple and conflicting voices that speak to a young person as she attempts to define herself within her peer group, her family, society, and with regard to her own values and sense of self-worth.

A cultural element might become a resource that is used to think about the past, generate alternative possibilities, or define future pathways. In this regard, when used as a symbolic resource, a cultural element might play a fundamental role in the reconfiguration of a person's life narrative and may therefore contribute to enhancing the person's agency on her own life trajectory. (Zittoun \& Grossen, 2013, p. 105).

In their study of students' use of cultural elements (philosophy or history texts) to construct a sense of continuity of self across spheres of experience (school, life outside of school), Zittoun and Grossen (2013) examined five types of dialogue at work: ${ }^{3}$ distant dialogue, actual dialogues, auto-dialogue, dialogue between situations, and dialogue with material objects, or "non-human actants" that frame human interaction. ${ }^{4}$ This model includes dialogues one may have with internalized others (Marková, 2006), such as in dialogue between situations. In connecting various spheres of experience and temporalities (the now of the current situation and the then of the situation invoked in the imagination), such dialogues link various facets of one's own self. The interaction of these various forms of dialogue produce dialogical tensions: "Under some conditions, such inner tensions might bring the person to reflect or to find new creative solutions that might yield new ideas and actions. Of course, people might also want to reduce tensions by repressing some voices or complying with others" (Zittoun, 2012, p. 101).

Whereas Zittoun and Grossen (2013) examine dialogical processes involving cultural elements already in circulation in the social world, the analysis presented here examines dialogical processes at work in the creation of a new cultural element, a radio feature story by two Mexican immigrant high school youths, Tania and Yoli. I explore how the inter-animation of these varieties of dialogue set in motion through the creation of the feature story, gave rise to dialogic tensions that may have played a role in developing greater self-consciousness, agentive re-positioning in their social fields, openings to new understandings and possibilities for taking action toward change. Following Freire (2000/1970), I also consider the implications of externalization within dialogical processes. This is the process through which people develop conceptual tools to work on, and alter not only themselves but also their environments, "to create new settings, social destinations, personal and group trajectories, and means for producing them" (Freire, cited in SoutoManning \& Smagorinsky, 2010, p. 44).

The following questions guided this inquiry: What types of dialogue can be inferred in the production of the feature story (Grossen \& Orvig, 2011; Zittoun, 2012)? What dimensions of dialogical self and self (re)positioning come into play (Hermans \& Hermans-Konopka, 2012; Zittoun, 2006)? How does the interanimation of the different types of dialogue generate dialogical tension that may create openings for self-

\footnotetext{
${ }^{3}$ This typology of forms of dialogue originated in the work of Grossen and Orvig (2011).

${ }^{4}$ The authors reference Latour's (1996) notion of non-human actants.
} 
authoring, shifts in perspective, and dialogical action? (Freire, 2005; Holland et al., 1998; Zittoun \& Grossen, 2013).

\section{Research Context and Methodology}

Youth Radio and Radio Arts was created in 2006 in the Rocky Mountain region of the western United States as an educational innovation with the goal of offering an alternative to remedial ESL language and literacy practices and promoting youth agency in and out of school. The program incorporates elements of multiliteracies (TheNewLondonGroup, 1996), critical language teaching (Norton \& Toohey, 2004), youth media (Goodman, 2003; Soep \& Chávez, 2010), and community based arts education (Heath \& Smyth, 1994; Heath \& Smyth, 1999), in order to promote personal, social, and academic development among immigrant youth, while creating greater access to digital technology and communication media. The program was designed to create a network of independent media professionals, artists, and community activists to support the literate, artistic, social, and personal development of Latina/o youth.

The case study I present here - Tania and Yoli's feature story production - is drawn from an ethnographic study of a Youth Radio and Radio Arts program conducted in 2010-11 in a multi-grade (911) high school class that combined an English as a Second Language (ESL) class with an academic support class based on the AVID model. ${ }^{6}$ The combination of the AVID and ESL classes in the Youth Radio and Radio Arts program brought the two teachers and myself into a co-teaching relationship. The teachers, with support from the administration, agreed to combine their two classes and devote five days a week to the Youth Radio program, one hour and a half each day, plus two hours after school for field trips and computer lab.

The year during which this ethnographic study was conducted, I was on sabbatical leave and was sole researcher in the Youth Radio and Radio Arts program. I played multiple roles - participant observer, co-instructor, and program director - and spent four days a week in the classroom as well as after school computer lab and some evenings or weekend field trips. My six years of previous experience in the school district directing arts and media programs at the middle school level facilitated my entry to the high school. ${ }^{7}$ Entering the classroom I was well aware of my position of privilege and power vis-à-vis the participants in the program - both teachers and students - as a university professor and white, middle-class woman who brought funding to the school-based program. I was also aware that perceptions of my social position might limit my access to emic, or insider perspectives, of the student participants and their psychosocial processes. To reduce the power distance, I participated in all informal after school activities including field trips, and engaged in playful, friendly conversations with students on a daily basis. I attempted to include the teachers and students as active agents in the research process: students sometimes asked to video record classroom activity or interviews, which I allowed them to do. Teachers, mentors, and students provided ongoing feedback on my interpretations of the meanings that were being constructed in the context, and I shared chapters of my book based on the study as they were completed (Walker, 2014).

The paid mentors who participated on a weekly basis throughout the year included a bilingual radio and print journalist and a radio broadcaster, both volunteers at the local community radio station. A theater professor, actor and director originally from Mexico, was the program's artist-in-residence in the fall. A Chicano poet and novelist served as writer-in-residence in the spring with support from a state humanities

\footnotetext{
${ }^{5}$ ESL is an acronym for an educational program known as "English as a Second Language"

${ }^{6}$ AVID: Advancement Via Individual Determination, is an educational intervention designed to raise the educational achievement of underperforming students, typically minority students. ESL: English as a Second Language classes, at the time of this research in this school, pulled students out of content-area courses for intensive, typically remedial English instruction.

${ }^{7}$ In addition to Youth Radio and Radio Arts, I co-directed an after-school arts and media program called Poets and Artists Networked (PAN) for four years (Walker, 2003).
} 
agency. A hip-hop DJ talk-show host and community-activist mentored the students after school in the computer lab and at the radio station: he conducted two interviews with students in the studio that were broadcast on the air.

The 18 students who participated in the Youth Radio and Radio Arts program were from workingclass, undocumented immigrant families in the USA. These included 15 Latina/o students, two Nepalese, and one Russian, with equal numbers of girls and boys: 15 of the 18 students had been labeled English Language Learners. The students lived in trailer parks or federally subsidized housing: none of them had a computer at home. While the high school was considered the magnet school for bilingual students in the city, the students I came to know felt segregated in a separate wing of the school, excluded from the majority population in classes and social spaces, and subject to racially motivated micro- and macro-aggressions, including graffiti that read, "All Latinos will die on October 23." This specific social setting was shaped by wider ideological and political forces, including generalized anti-immigrant sentiment in U.S. society, racism against people of color including those who speak languages other than English, economic exploitation, and immigration enforcement policies that created an environment of uncertainty among youth who feared being separated from their families due to deportation.

\section{Methodology}

To understand how the radio program supported dialogical processes among participants, I combined elements of interactional ethnography (Castanheira, Crawford, Dixon, \& Green, 2000; Green \& Wallat, 1981), and sociocultural psychology with a semiotic focus (Zittoun \& Grossen, 2010, 2013). Interactional ethnography joins a cultural anthropological perspective on social life (Geertz, 1973/2000; Spradley, 1979) with a sociolinguistic perspective on the study of language in use (Gumperz \& Hymes, 1972; Heath, 1983) to examine how people create meaning, identities, and opportunities for agency through the ways they act and react to each other through the use of language, including verbal and nonverbal semiotic systems with attention to social, cultural, and political processes (Bloome, Carter, Christian, Otto, \& Shuart-Faris, 2005). Sociocultural psychology provides the analytical tools to explore the experience of the individual as shaped by her inner life intermingled with activity and cultural tools, present and distant others, related situations, the spatial and temporal dimensions of experience and inner-dialogues, and the dynamics of personal sense-making (Zittoun, 2017). For the end of the year interviews with students, I adapted a protocol created by Zittoun and Grossen (2010) in their longitudinal study of the use of cultural elements (philosophical and literary texts) by high school students in bridging the contexts of school and life outside of school.

Sociocultural psychological approaches to dialogicality can help address the gap in educational research that tends to focus only on those dimensions of dialogue that are visible/audible and measurable. Recent advances have been made by researchers in this tradition to connect inner dialogicality to institutions and larger social processes, beyond interpersonal relationships to account for historico-cultural and ideological dimensions of dialogicality (Gillespie \& Zittoun, 2013; Grossen \& Orvig, 2011). Interactional ethnography provides us with complementary set of analytical tools that allow us to develop "the big picture" and depth of field, through long term immersion in the field and analyses of data across time and contexts. In the case study discussed here, for example, knowledge gained from years in the field working with Mexican immigrant community allowed me to grasp the full extent of tension among the voices captured in the feature story, due to my knowledge of cultural discord between the Mexican immigrant community and the dominant social group - White middle and upper-class families - regarding teen sex. I also was aware of how the topic was treated by Tania and Yoli in a digital story they created previously, and I was able to identify curricular texts that were brought into dialogue with their feature story. The interactional 
ethnographic approach allowed me to expand my analyses of dialogic processes in time and space, and thereby develop a perspective with enhanced depth of field and a more nuanced interpretation of the data.

\section{Data Collection and Analysis}

The data sources used for this analysis included audio recorded interviews, student work, and observations and video recordings of learning activity in the classroom, the radio station, and the school computer lab during and after school. The audio and video recordings - constituting approximately 240 hours - were summarized and time-stamped by a research assistant. Portions of audio and video summaries were then selected for detailed transcription based on their relevance to the research questions and emerging themes. Coding followed Spradley's (1979) procedures for domain, contrastive, and taxonomic analyses of ethnographic interviews.

For this analysis I focused on the feature story due to its inherent dialogicality. Students were expected to represent and consider multiple perspectives on a topic they selected, which offered the potential for students to see "as if from the perspective of others" (Wegerif, 2013, p. 47), to see, hold, or feel from multiple views at once (Wegerif, 2017). Having identified the feature story and its production process as the anchor for the analysis of dialogical processes, I used the "backward and forward mapping" strategy proposed by Putney and colleagues (Putney, Green, Dixon, Durán, \& Yeager, 2000) to reconstruct Tania and Yoli's experience of the feature story project and their reflections on the process. I constructed a timeline of events, products, and processes related to the feature story with associated data records. I transcribed the feature story, my exit interviews with Tania and Yoli, and video and audio recordings of what appeared to be key interactions in whole class, small group work, and interactions with the radio journalist mentor Joe Richey. I conducted discourse analyses of selected transcripts, and a content analysis of the feature story.

My analysis is presented in three broad strokes. First, I situate the process and final product of the feature story in time and space. I then discuss the dialogical processes and openings for authorial agency that could be inferred from different types of dialogue involved in the process. Finally, I show how the feature story became a symbolic resource for other youth, in what I perceive to be a form of cultural, collective transformation.

\section{Overview of the Curriculum and Feature Story Genre}

Because Youth Radio and Radio Arts was designed as a community-school linked network that connected learners and learning to practitioners and their work in independent media and arts organizations, the program introduced a set of practices and material and conceptual artifacts that were new for both students and teachers. The curricular texts consisted of online multimodal stories taken from the Youth Media International website (YouthRadio, 2016), mainstream news organizations, the Center for Digital Stories (StoryCenter, 2009), oral and visual texts, guest speakers, and radio and digital stories created by peers and discussed in class. To produce the feature story, the students and teachers used audio and video editing applications, audio recording devices, flash drives, the internet, and the website application iWeb to create content for the program website. They conducted background research and evaluated sources on the Web; they composed interview questions, scheduled and conducted interviews, edited their own and others' recorded voices. They received peer and adult critique, and presented their work to a larger public, both in person and on the air. 
Curriculum and instruction were organized around activity cycles and genres, falling within three main domains: radio production and broadcast, multimedia production and digital design, and radio arts. These are presented in Table 1.

Table 1. Activity Cycles and Genres

\begin{tabular}{|l|l|}
\hline Activity Cycles & Genres \\
\hline $\begin{array}{l}\text { Radio production and } \\
\text { broadcast }\end{array}$ & $\begin{array}{l}\text { Youth commentaries (Oct.-Dec.) } \\
\text { Feature story: Our School Community (Jan.-May) } \\
\text { Work in the KPFW station studios (Oct.-May) } \\
\text { Vox pops (vox populi) (Dec., April) } \\
\text { "If I were mayor of this city I would ..." (in class) } \\
\text { "How can we make this city a better place for youth?" (in the streets) } \\
\text { Training sessions in the station studios } \\
\text { Interviews by radio personnel at the station }\end{array}$ \\
\hline $\begin{array}{l}\text { Multimedia production } \\
\text { and digital design }\end{array}$ & $\begin{array}{l}\text { Digital stories: Our Neighborhood Community, personal life stories (Oct.-May) } \\
\text { Website content development (Nov.-May) } \\
\text { End-of-semester presentations by students of their productions (Dec., June) }\end{array}$ \\
\hline Radio arts & $\begin{array}{l}\text { Radio skits (Oct.-Nov.) } \\
\text { Poetry writing and performance (Mar.-June) } \\
\text { Field trips to Chicano theater in a nearby city (Dec., April) }\end{array}$ \\
\hline
\end{tabular}

For each genre taught, we provided overt instruction for developing control of the specific genre focused on (a) the social purpose of the genre, including the kinds of people associated with the genre and how it is used to get something done, such the kinds of technology that are used; (b) the particular structure or organization of the genre; and (c) the language features that are typical of that genre. However, while students received explicit instruction in each genre, the teaching did not target an object of knowledge nor a stance toward the object of knowledge that would require distancing themselves from emotional and identification processes in order to focus on the genre techniques or forms (Rochex, 2004; Zittoun \& Grossen, 2013). In contrast, the program sought to help students develop a stance toward the voices and conditions impinging on their lives, using radio genres and communication technologies to shape their own narratives and those of their communities, rather than being mis-represented or overlooked in the media. The radio genres were taught in the program, following Freire (2005), to help students become aware of the connections between their own lives and society, rather than personalize their problems as their own. The texts used to model each genre were selected to encourage dialogue about generative themes drawn from the students' everyday lives (Freire, 2000/1970).

For the feature story, the class listened to, read transcripts of, and discussed examples of feature stories created by urban, multilingual and transnational youth. The unit was framed within the general theme of "Our School Community," with published online youth radio stories used as models addressing topics such as secret romance in school, and undocumented students - those with unresolved legal residency status - who aspired to attend college but faced the dilemma of ineligibility. The multimodal texts were heteroglossic (Bakhtin, 1981), representing a diversity of social languages, ideologies, and voices speaking English, Spanish, and African American Vernacular English. The structural elements of the feature story that were highlighted for students included, 1) the introduction which frames the problem drawing on background research, 2) three interviews representing divergent perspectives, 3) transitions between 
sections, 4) a wrap-up or "outro" with "a punch," and 5) the "tag," for example, "For Youth Radio at Beckwourth High, this is Tania Lendoza." Language features specific to the feature story included the different types of questions tailored to different types of interlocutors (an expert is asked different questions than a participant in an event), and a narration using a formal register and authoritative voice grounded in "the facts" for the intro and outro sections. The audio features highlighted for students included ambient sound designed to "bring the listener into the setting," along with an aural balance of voices and sound to create overall cohesion.

\section{Dialogical processes in "Teen Views of Sex," by Tania and Yoli}

In their feature story "Teen Views of Sex," Tania and Yoli explored adult and teen views about teen sex, supported by research and their own reflections on the subject. Their production made an already compelling topic even more interesting for their various audiences by including a range of voices: a mom, a male teacher, male and female teens, the producers themselves, and the "official research" on teen sex. In their exit interviews, both Tania and Yoli identified the feature story as her favorite project. Tania stated, "I got a lot of feedback on what sex really was to teenagers nowadays, and I now know what I can say to teenagers when they think of that problem, and I can have a better explanation to tell them what's right and what's wrong." When Yoli was asked if there anything she read, viewed, or listened to in class that affected her in any way, she responded, "Our feature story made me realize more what's there, not actually what it seems. I thought everyone lost their virginity their freshman year." Tania and Yoli's feature story was viewed by teachers and students as a slightly shocking, and courageous, an exemplary production that was one of two feature stories that achieved "broadcast quality" and was aired on the radio. The feature story was played as a model of the genre for students in Youth Radio and Radio Arts in subsequent years.

As noted above, the feature story is inherently dialogical as it brings together and juxtaposes multiple perspectives on a controversial topic, in dialogue with the narrator. The producer arranges these voices into a single, unified whole while retaining the tension among diverging perspectives. Additionally, the feature story is clearly addressed to a particular other, implying an orientation toward "a specific conceptual horizon, toward the specific world of the listener" (Holland et al., 1998, p, 178).

The following is a full transcription of Tania and Yoli's feature story.

Transcript 1: "Teen Views of Sex," by Tania and Yoli

1 Tania Today, sex is a subject that is openly discussed among teens. It's a subject that seems to

$2 \quad$ lose its value more and more as teens evolve into a new era.

3 Yoli I think nowadays teens want everything now. We don't want to work hard for something

$4 \quad$ and then have it pay off in the end.

5 Tania Especially sex. The age of teens having sex is getting younger and younger. During this

6 process, we interviewed a mom who shared with us her opinion on how sex is viewed by

7 teenagers nowadays.

8 Mom It has changed because it seems to me that most girls don't have respect for themselves, for

9 the way they act, the way they dress. They lack lots of respect.

10 Tania [to radio audience]. We walked along Boulder High halls and asked a senior and a

11 freshman on what they thought about sex to get the views of both a newcomer to high

12 school and someone who has been through it all.

13 Tania [to interviewees]. What is making us teens want sex so bad? Is it that it gives us a feeling

14 of being older and experienced, or is it just another oh-everyone's-doing-it type of thing?

15 Boy Oh my god! But, I think it's really fun. [laughs] 


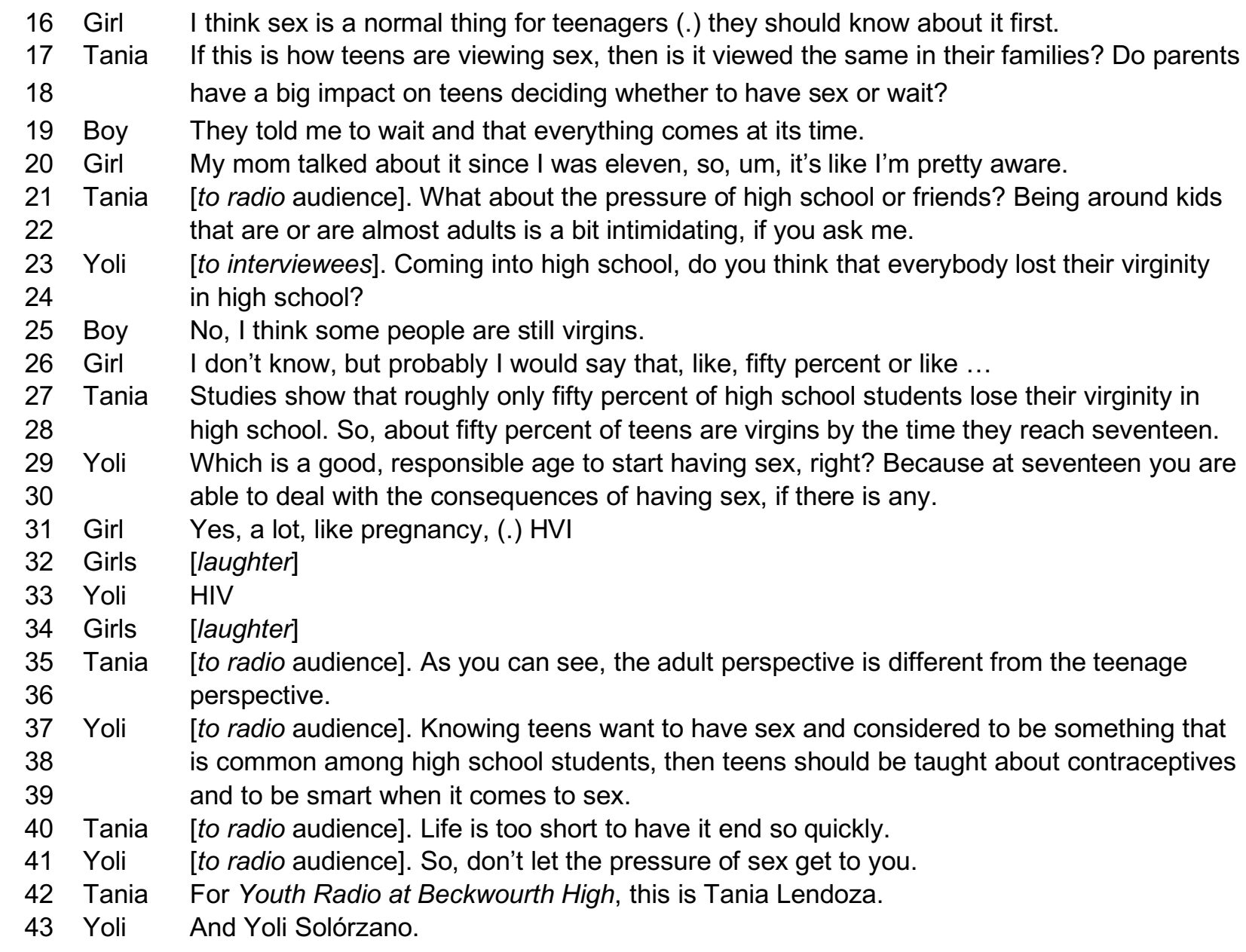

\section{Situating the feature story in time and space}

Before examining the dialogical processes that can be inferred from the feature story itself, it is necessary to first situate the story within space-time dimension of its production. The feature story was produced in school during school time, as a class assignment for which students received a grade, with learning objectives aligned with state standards as required by the school administration. The general curriculum of this high school privileged what Matusov et al. (Matusov et al., 2016) call a "technological approach" to education, which assumes that,

\footnotetext{
"skills" or "knowledge" are garnered in pursuit of preset curricular endpoints (i.e., curricular standards). Since the goals of the technological approach are divorced from the students' personal goals, values, and interests, they are incompatible and irreconcilable with what we idealize as the true goal of education, education for agency. (p. 162)
}

The students in the program, including Tania and Yoli, viewed school as tedious and marginalizing (Walker, 2014): their classes featured remedial reading and writing, worksheets, and a focus on how to answer the teachers' and textbook questions. The feature story assignment, part of the school curriculum, therefore, would have been associated with the authoritarian, "monologic" (Bakhtin, 1991) school discourse. 
However, over time, the feature story assignment and radio program more generally came to be acknowledged by students as opening spaces for expression of their perspectives and voices. The following is a sample of responses from exit interviews with student participants:

In Youth Radio you learn how to express yourself and how to let people know what you think and talk for yourself, but also for other people - to express your opinions. (Sonia)

In other classes we have to be most of the time quiet and just take notes. Notes, notes, notes. We never get to express ourselves or make comments because in other classes we just have to take notes and just sit there. (Yoli)

In this class you say what you're thinking, not just like answering teachers question. In other classes you only talk about the subject, not your opinion. (Delfina)

Youth Radio gives us a chance to express what we feel and let others know what we think about topics. (Yoli)

The pre-existing contradiction between school and program ideologies about personhood and learning would have created a dialogical tension in the feature story from the very start. By choosing to include the school counselor as one of their interviewees, it seems that Tania and Yoli elected to directly confront the authoritative school discourse by bringing this voice into relationship with voices from their MexicanAmerican peer group and family at home.

In their radio story, the girls represent some of the contradictory perspectives in U.S. and Mexican society and different generations on teen sex: "As you can see, the adult perspective is different from the teenage perspective," Tania concludes. The interviewees in this feature story could be thought of as emblematic persons representing distinct views on the subject of teen sex: a mother, a school counselor, and sexually active teens, both male and female. Beyond the spoken voices, it could also be inferred that these radio voices represent the externalization of voices from an inner dialogue about when teens should become sexually active. The voices in the feature story also signify and weave together distinct social spaces and times: the time-space of home and family; of a childhood in Mexico; of past selves before the "culture of romance" (Holland \& Eisenhart, 1990) became so prominent in their teen lives; the extracurricular time-space of social media; of face-to-face gendered peer groups where sex is discussed; the time-space of science and public health policy explored on the internet; and the time-spaces of school, in and out of the classroom: the trip to the counselor's office would have represented an escape from the classroom space where youths' bodies are controlled and immobilized in rows of desks, even during Youth Radio class (except during radio improv and sometimes during poetry workshop).

From a Bakhtinian perspective, the conflicting voices embodied in the radio story represent ideological standpoints that the girls orchestrate as a way of responding to the dilemma that confronts them - when teens should begin to have sex. In this polyphony of voices and ideologies, the girls seem to come down on the side of the societal, school, and parental discourse that encourages teens to wait until marriage or adulthood (itself an ambiguous notion as it differs in Mexico and the United States). This can be seen as they take an authoritative and evaluative stance toward teen pregnancy, giving advice - consejos - to other teens: "Don't let the pressure of sex get to you" (lines 37-41); "We [teens] don't want to work hard for something and then have it pay off in the end" (lines 3-4). However, they do not simply "ventriloquate" the parental and dominant societal discourse. The authors add their own words, as when they pose this 
question: "What about the pressure of high school or friends? Being around kids that are or are almost adults is a bit intimidating, if you ask me" (lines 21-22). The end product is a dialogic object in which the societal message about teen sex appears to become "internally persuasive discourse" (Bakhtin, 1991) for the authors: it appears as if the school discourse has been taken into their own, has intermingled with their own words, becoming "half [their's] and half someone else's" (p. 376).

\section{Actual Dialogue}

Actual dialogue, or dialogue in praesentia, can be face-to-face or mediated by technology. Actual dialogue involves more than one speaker, and the circulation of discourse as the result of interactions (Zittoun \& Grossen, 2013, p. 119). The production of a feature story involved several types of actual dialogue: dialogue between the co-producers, dialogue with the radio mentors, and dialogue with interviewees. In the following section, in addition to describing the types of actual dialogue found in the feature story production process, I discuss two related dimensions of dialogicality: aspects of the dialogical self that can be inferred, and the re-positioning of self in one's social field.

Dialogue between the co-producers. Tania and Yoli spent a good deal of time in dialogue, both at school and out-of-school. Production work on the feature story occurred primarily after school in the computer lab, amid intense conversations, excited laughter, and clear signals for the need for privacy and no adult intervention. Tania and Yoli both lived in the same federally subsidized, low-income housing projects, and shared common childhood and early teen experiences. In their earlier digital story, the girls juxtaposed images of young teen girls and older gang-identified males with the following narrative:

Transcript 2: Excerpt of digital story titled "Back Then," by Tania and Yoli

1 San Juan is where we live. It's a neighborhood that is mostly populated by Mexicans.

2 Back when we were ten, in elementary [school], everything seemed fine.

3 We had playgrounds, wide open fields, friends.

4 Everything seemed perfect in our own little world...

5 But then came 13, when we started to grasp the concept of what real life is...

6 Weed [marijuana]

7 Cocaine

8 Alcohol and sex.

9 It's all part of the ugly world the cool kids are living.

In both their digital story and their feature story, the girls explore the challenges they faced growing up exposed to young adult male drug abuse and sexual activity. As Tania states in the feature story regarding the pressure on teens to have sex at an early age, "Being around kids that are or are almost adults is a bit intimidating, if you ask me." The girls examine these difficult questions through extensive dialogue over a period of approximately four weeks. Together they co-construct a feature story that draws together some of the contradictory perspectives on the topic of teen sex, and begin to take a stance however tentative, as evidenced in the hesitant tone of Tania's final statement above - toward the voices that are impinging on their lives, with real consequences in this key moment in their life trajectories.

Dialogue with the radio journalist mentor. Grant funding obtained for this research allowed me to hire professional writers and artists as mentors for students in the program. Mentors from the local community radio station worked with students twice weekly from October through May. The continuity of mentor support allowed for relationships of trust to develop, and for students to benefit from extended exposure and engagement with professionals and their practices from independent media and arts organizations. An important component of the instruction and production process of radio stories was 
extended dialogue with the journalist mentors. In these small group or individual sessions the mentors helped students elaborate and refine their ideas and language on their chosen topics while providing guidance on the genre features and approaches to writing and speaking for the radio. This mentoring by journalists in speaking and writing for radio was identified by several students as critical to developing language skills and a public voice for communication in the public media sphere.

Joe Richey was the program's journalistic writing coach and "managing editor" for the student radio productions. He modeled the feature story using a syndicated story he had produced on the Mexican-U.S. border zone. Students pitched their ideas for stories to him, and he decided when written drafts were ready to be recorded. Joe showed students how to connect a personal issue to the larger sociocultural context. In Tania's radio commentary, for example, she began her writing process by describing her own situation at home. Her final product "All Teens Need a Second Home," generalized her personal experience to other teens who might suffer forms of abuse at home. These dialogues with Joe facilitated the negotiation of the numerous discourses that students brought with them to the classroom from home, peer, and national cultures.

Transcript 3: Excerpt from feature story "Teen Views of Sex," by Tania and Yoli

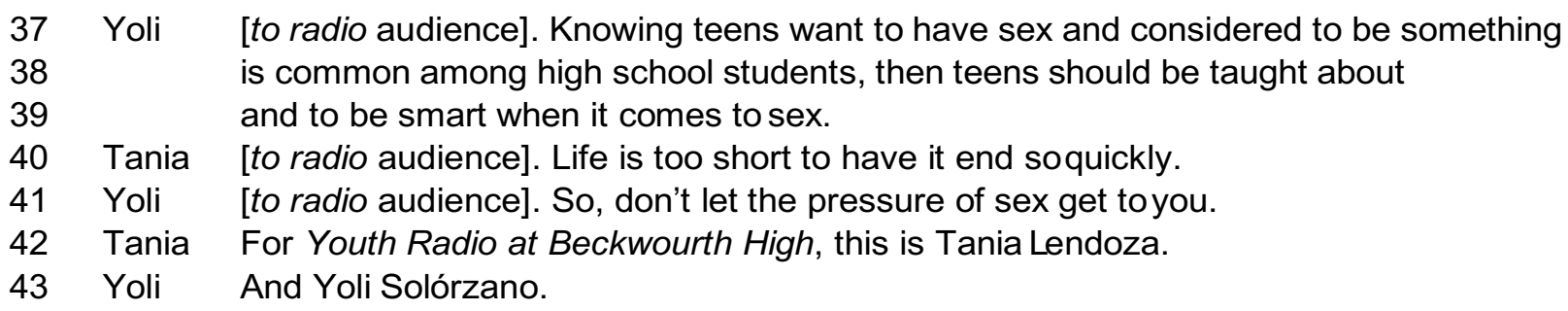

Ethnographic data from across the year helped contextualize the construction of the authoritative voice of the co-producers/narrators heard in the feature story. Interactions recorded between Joe Richey and the girls indicated that he encouraged the girls to frame their feature story as a Public Service Announcement (PSA), though this was not intended as part of the originally modelled genre. The PSA "speech genre" would have resonated with Tania whose previously produced radio commentary closed with the statement, "I stand for my generation and send a message to all teenagers to stay strong, brush your shoulders off, and keep walking forward." The authoritative tone expressed in the feature story reveal an emerging stance among Tania and Yoli toward the voices - especially those teen and young adult males - pressuring girl teens to have sex at an early age. This stance developed in part through extended dialogue over time with Joe Richey.

Dialogues and the dialogical self in the interview process. The actual interviews conducted for the feature story involved several dimensions of dialogue, and call attention to Hermans' and co-authors' notion of dialogical self (Hermans \& Hermans-Konopka, 2012). Developing the interview questions required that the girls orient themselves toward their interlocutors in order to frame meaningful questions. At the same time, the questions needed to be framed in such a way that the interviewees would orient themselves to the girls' interests and the central concern of the story. Rommetveit (1992, cited in Wegerif, 2017) might have called this circularity of reference, "attunement to the attunement of the other." Preparation for the interviews included rehearsals in posing follow-up questions, which required careful listening and on-thespot improvisation of new questions. The process of anticipating and building on the thoughts of the other would have intermingled the mind of the interviewer with that of the interviewee in the moment. Later, during the editing process, these dialogical movements became objects of reflection and autodialogue, as I discuss below. 
Autodialogue is the type of dialogue that a person has with herself, as when one speaks to oneself in the mirror, internally or audibly. While not directly observable, autodialogue can be inferred, according to Zittoun and Grossen (2013), by the presence of certain discursive markers in a person's speech, such as the use of pronouns indicating different enunciative positionings, "or the use of opposition markers such as 'but,' 'on the other hand,' etc. ... All these markers can be seen as indicators of dialogical tensions between various facets of the self. (p. 119). The case of Gaëtane is used by the authors to illustrate aspects of autodialogue. In her reflection on her use of music to mediate psychological states, Gaëtane presents herself in two different aspects: "...the ' $l$ ' who is in a good mood and the 'l' who feels unhappy" (p. 119). Gaëtane's autodialogue about her choice of music depending on her moods shows, according to the authors, that she looks after herself, as if she were another person. Her discourse also reveals different "I's" in different moments in time.

Zittoun and Grossen's (2013) concept of autodialogue, in this sense, is suggestive of the notion of shifting "I-positions" within dialogical self-theory, though the authors refrain from citing Hermans and colleagues in relation to autodialogue. (e.g., Hermans \& Hermans-Konopka, 2012). In my analysis of Tania and Yoli's reflections on the feature story interview process, I make use of elements of the concept of shifting "I-positions" to elaborate the presence of autodialogue in the feature story production, including the girls' reflections upon the process.

Tania and Yoli's reflections on the interview process, shown in Transcript 4 below, appear to have centered on three facets of the experience: the girls reflected upon the embodied voices of the speakers, upon the thought processes revealed in the interview, and on the perspectives communicated by the interviewees. In her exit interview, Tania describes the dialogue mediated by a recording device as a moment when she simultaneously sees and interacts with the interviewee, while assuming that she is being seen by the other as slightly audacious and transgressive: a girl asking boys, men, and a mother about teen sex. It could be said that Tania and Yoli thus position themselves as both the self (I) as the knower, and the self (me) as the known (Hermans \& Hermans-Konopka, 2012).

In conducting the interviews for their feature story, Tania and Yoli positioned themselves as both the self (I) as the knower, and the self (me) as the known (Hermans \& Hermans-Konopka, 2012). In Herman and colleagues' theory of the dialogical self, the self is composed of temporary positions in relation to other real or imagined people and objects, shaped by interactions, space, time, and recurring situations (Hermans, 2001; Hermans \& Gieser, 2014; Hermans \& Hermans-Konopka, 2012). In her exit interview, Tania describes the dialogue mediated by a recording device as a moment when she simultaneously sees and interacts with the interviewee, while assuming that she is being seen by the other as slightly audacious and transgressive: a girl asking boys, men, and a mother about teen sex. In the following interview with me, Tania describes both a self as interviewer (self as knower), and self as seen through the eyes of the male teacher (self as known):

Transcript 4: An Interview between Tania and Dana (05/02/11)

1 Dana: Has youth radio helped you develop more self-confidence in any way?

2 Tania: It has. Just because you know we show our feature stories and people are seeing

3 what we did specifically, what we worked for, how we like developed out

$4 \quad$ narration. And we play them [to the class] in the end. At first it's a little shy but like

$5 \quad$ in the end you see how they [the interviewees] really see it and they're

6 [interviewees or audience?] not laughing and cracking jokes about it. They're 
10 Dana: That's interesting. I hadn't thought about that. What was it like to interview people

[interviewee or audience?] really taking it seriously so...

Dana: So the audience helps you develop confidence?

Tania: Definitely. who weren't necessarily your friends for your feature story? Was that difficult?

Tania: At first it was just because they take you like as being always the funny friend someone you can count on but when it comes to serious work like you know interviewing on their perspective on sex, they take it like, they'll accept it, but it's a little awkward at first for them because now they see you all serious.

Dana: Now you're talking about your friends, right? Right. And what was it like it like to (.) Did you interview people that you didn't really know?

Tania: I did. With Selena it was. Or an adult, or (..)? Oh yeah. Mr. Lyndberg, I think it was. He's a gym teacher here.

Dana: He teaches Sex Ed? Health and Sex Ed. So what was it like to interview him?

Tania: At first it was like a little nerve-wracking just because he is an adult and he is a male so it's like and we're both girls so it's like, at first it was a little nervous but after you know, he adjusted to it and it was like, he was [thinking], "This is for their grade," so he was like, "So." He did help us out, so it definitely worked out.

Dana: How did you feel after you interviewed him, after going through

Tania: Afterward it was a little more comfortable and like now every time I see him in the hall it's always like, "Oh hey how are you?" "Good." So I think it definitely built up my confidence to talk to people when I need to.

Dana: And maybe developed relations with other people that you didn't know? Like him? Like now you say hello and stuff like that.

Tania: Yeah.

In this excerpt, Tania first describes the internal experience of the interview with the male teacher: "At first it was a little nerve-wracking" (Line 2). She then describes herself as the girl who is seen by the male teacher (the self as known): "He is an adult and he is a male... and we're both girls" (Lines 22-23). She then goes on to offer a form or reported inner speech on the part of the teacher, describing the situation from his perspective: "[H]e was thinking, "This is for their grade" (Lines 24-25). Tania is thus representing herself from two different perspectives simultaneously, looking at herself from the inside and the outside, occupying two different positions. As Bakhtin (1981) suggests, constructing "outsideness" is a way of representing ourselves to ourselves from the vantage point of others, a way of standing apart from immediate experience while still defining it as ours through the arrangement of perspectives and voices (Holland et al., 1998).

Repositioning through dialogue in interviews. In addition to the shifting I-positions of the interviewers noted in the discussion thus far, social positioning processes were also important dimensions of dialogicality noted in this case. Social positioning involves identity processes, the repositioning of the person "in her social and symbolic fields" (Zittoun, 2008, p. 166)), and new representations of past and possible future selves. In reading or listening to the feature story one is struck by the reversal of roles in 
terms of who gets to ask whom about sex: in this instance, it is girls asking boys and adults - both male and female - in ways that are usually taboo in school (at least in U.S. society in the Rocky Mountain region). The girls challenge hegemonic gender roles in their production process. In the course of the interview Tania's positional identity shifts from that of a shy and funny girl (someone who jokes around), to a radio interviewer who is to be taken seriously. Tania reveals her awareness of the shift in her positional identity when she points to the social awkwardness the shift caused among her peers:

Transcript 5: Interview between Tania and Dana (05/2/11)

31 At first it was just because they take you like as being always the funny friend

32 someone you can count on but when it comes to serious work like you know

33 interviewing on their perspective on sex, they take it like, they'll accept it, but it's a

34 little awkward at first for them because now they see you all serious

Similarly, Tania's reflections on the interview with the school counselor, described in her interview with me on May 2, 2011 (Transcript 2, Lines 22-25), highlight the discomfort felt by the girls as well as the adult male teacher during the interaction. However, she explains that he was forced to adjust to their agenda, reversing the gender and age hierarchies. It is interesting to note that in subsequent encounters in the school hallways it was she, not the male teacher, who initiated the informal, friendly greetings. According to Tania, this experience built her confidence in talking to people, including those outside her usual spheres of experience. The shifts in identity positionings that she describes, while momentary and specific to the interview process, may have created openings for the girls to imagine alternative gender roles and "possible selves" (Cole, 1996).

Another aspect of re-positioning that emerged in Tania's reflection on the interviews she and Yoli conducted, had to do with transitioning from someone who was not taken seriously, to someone who could be both lighthearted and someone of consequence. Before, she was seen only as "the funny friend" (Line 16) or as she says at another point in the exit interview, "someone who is outgoing and funny and different." Now, she also wants to be seen as someone to be taken seriously, whose opinion or stance - what she calls "voice" - matters.

Transcript 6: Interview between Dana and Tania (05/02/11)

1 Dana: Can you think of some concrete examples of things that you've done in

$2 \quad$ this class that have helped you develop your voice?

3 Tania: I would say the teen sex views just because, like it gets, like, you know,

$4 \quad$ you can tell that my voice is very serious about that and before I wouldn't

5 be able to be so serious about such a small thing. And now I'm more

$6 \quad$ serious and I can project my voice to let them know that I am being really

7 serious about the situation.

It could be inferred that work on the feature story led to a transformation in Tania's relationship to herself, as well as to others and to objects of knowledge - in this case teen sex. She learned that if she worked hard, developed confidence and the proper communication tools, she would be taken seriously she could be "successful." In her exit interview Tania reflected, "I learned that I can be successful you know if I (..) because I did get a little push in Youth Radio like they were like, "go and interview" you know be confident in yourself and you know and just what's in me, and go use it outside." This quote from Tania recalls Freire's (2005) notion of dialogic action and his interest in externalization as the process through 
which people acquire tools to work on, and alter, not only themselves but also their worlds - "to be confident in yourself...just what's in me, and go use it outside."

\section{Dialogue among situations}

The feature story shows Tania and Yoli moving among and linking several situations and social spaces: home (interview with mother); her peer group (interview with other youth); school (interview with the assistant principal); and the distant world of public policy and scientific research. The interview process placed her in a location of dialogical tension between these various situations, allowing her not only to explore and synthesize a range of diverse perspectives on the topic. It also enabled her to examine her own knowledge and feelings on the subject of teen sex in the context of our exit interview: "Sex is a thing that some kids thought everyone did by their junior year. But we learned that's not true." While the process may have been emotional tumultuous - "It does like bring out a little happiness or a little sadness or a little angriness, you know, towards like what I'm living or how I'm living and so forth," Tania and Yoli came through the process feeling not only more knowledgeable, but also empowered to share her knowledge with other teens "so they don't make the same mistakes."

\section{Dialogue with distant imagined others in the local community and "on the air."}

Distant dialogues refer to dialogues with absent parties, living or fictional, in the present past or future (Zittoun \& Grossen, 2013). In the program there was frequent talk of radio audiences, including Kareem - the Hip Hop DJ and radio host mentor mention - that "you never know who might be listening," and "there may be millions of people listening all over the world" (through Internet radio). The students were interviewed at the community radio station and learned how to use the audio board there. They met professionals and volunteers to talked to them about the local community audiences they would reach. The students thus worked with these potential community and global internet-based audiences in mind. When Tania and Yoli's feature story was broadcast on the radio and the internet, they might have imagined what people "out there" thought about their piece, and about them. I would argue that this sense of a projected self (on the airwaves), together with an enlarging sense of community through their participation in the radio station and interactions with individuals from other community-based organizations, contributed to an expanding sense of self and realm of potential action. The following conversation reveals how the teacher Ray and I together interpreted changes we were observing in students' sense of themselves, in terms of voice, agency, and the potential for dialogic action:

Transcript 7: Conversation between Ray, the ESL teacher, and Dana (05/10/11)

1 Ray: [An outcome of this program has been] students feel they belong to a greater community,

2 and once they do that then they feel they're important, and they have a

3 voice. I think that the community has made them feel that-the Lyles, the Joe

$4 \quad$ Richeys, that they belong to this community

5 Dana: What community?

6 Ray: [Our city]. And our studies on community, school, their neighborhood, combined

$7 \quad$ with people from the community coming to them and saying, like Tim lately saying,

$8 \quad$ "You guys have something to say." Not just teachers-teachers are supposed to say

9 that. So I think all that contributes, and now they're starting to have their voice,

10 They're starting to say, "Yeah, I do have something to say."

11 Dana: Sandra said something interesting to me. She said, "We start looking into issues and 
problems in our communities and then we feel like we wanna do something about it."

13 Ray: Yeah, I think when you ask them to, it's saying, "you're important, tell me."

\section{Dialogue Between Humans and Non-Human Actants}

Cultural elements are semiotic devices made out of signs in a material, perceptible form that carry meaning that is socially shared (Zittoun, 2006). A feature story is composed of semiotic units of introductory music, images, narration, ambient sound, and discourse to which other people attach meanings that come to be shared through cultural processes such discussing and critiquing a feature story in the classroom. When someone creates a new feature story, they use the existing genre rules of composition (internalization), while adding new elements or new translations of existing forms through processes of externalization (Valsiner, 2007b). These objects can be viewed as creating a space of dialogical tensions between different times, spaces, and multiple voices. In producing their feature story Tania and Yoli entered into dialogue with feature stories that were selected to model the genre. These feature stories were produced by other youth and made available to our students in the context of whole class listening and discussion sometimes accompanied by transcripts.

One cultural element with which Tania and Yoli seem to have been in dialogue during their production, was a feature story presented in class five months earlier entitled Secret Dating. In this feature story a Spanish-English bilingual teenage girl explores the dilemmas faced by a teen whose parents, she believes, disapprove of her having a boyfriend. The author interviews her mom and her boyfriend. It seems that the topic and the voices in this radio story found resonance with Tania and Yoli, and triggered emotional elaboration and reflection on the dilemma addressed. Elements of the Secret Dating story entered into the creation of their own feature story, such as the types of people selected for interview (mother, boyfriend), the stance of the interviewer taken toward the mother (seeking an opinion rather than advice), and the general theme of teen romance and sex. This example shows the forward motion of change that can be engendered through dialogue with a cultural element, or non-human actant. In this case the girls used an existing cultural element - Secret Dating - for interpreting their own experience and conferring sense to it. They then combined words, themes, and images from that symbolic resource with their own words, images, and ideas in a new creation. The new feature story created space for self-authoring as well as for semiotic work among other youth going forward, as I will explain.

With the growing acknowledgement they received for their compelling radio production, Tania and Yoli began to see themselves in a new light, as serious more mature teens who could shape the perspectives of younger siblings and other teens through their radio stories. As noted above, Yoli's favorite project in the Youth Radio and Radio Arts program was the feature story, because it made her "realize more what's there, not actually what it seems," and because she appreciated gaining insight into the dialogical nature of human society: "there's always two sides to a story." Tania's favorite project in the program was the feature story, because in the process she gained the knowledge and communication skills that would allow her to shape the perspectives and futures of younger teens and siblings:

My favorite project was the feature story because I got a lot of feedback on what sex really was to teenagers nowadays, and I now know what I can say to teenagers when they think of that problem, and I can have a better explanation to tell them what's right and what's wrong.

The feature story was one of many projects in the Youth Radio program that permitted Tania to link program-based knowledge and activity to spheres of experience outside school, while gaining the tools with which to transform her already strong sense of social responsibility into action for social change in her 
community. Both Tonia and Yoli's reflections upon the interview and production process revealed growing self-awareness about themselves and their positionality in relation to others. Their enhanced sense of agency was expressed by Tania in relation to shifting identity positions in the gender hierarchy, as well as their narrative of becoming mature teens with the knowledge and communication tools necessary to inform other teens about the realities of teen sex.

\section{Concluding Remarks}

The purpose of this paper was to provide a fine-grained analysis of the dialogical processes that could be inferred from the production of a radio feature story "Teen Views of Sex." Drawing on the work of Zittoun \& Grossen (2013), I examined five types of dialogue to understand how their interaction produced a dialogical tension that created space for reflection and openings for self-authoring, as well as taking action in the world. Findings from this case study called for consideration of related approaches of positioning and dialogical self theory (Hermans, 1999; Hermans \& Hermans-Konopka, 2012).

Bakhtin (1981) wrote that struggling with another's discourse is crucial for the development of an individual's consciousness. When voices become critically interanimated, the person must take a position among and toward the voices. In the case discussed here Tania and Yoli used the feature story genre to juxtapose competing voices and took a stance toward the voices by stating their conclusions about what they had learned, drawing in part on their own experience. Further opportunities for reflection were offered in the hour-long exit interviews, which constituted a kind of "thinking space" (Perret-Clermnot, 2004) for students and the researcher: "The thinking space is the frontier of freedom in the psychic activity in which the individual elaborates the perceived reality in order to represent or symbolize it and to become able to reflect on it" (Perret-Clermnot, 2004, p. 3).

Making dialogical tools such as the feature story available to youth in educational settings is critically important. Adolescence is a time when the person is subject to an incoherent flow of images, voices, narratives, identities and expectations for who they should be and become in the various cultural worlds they inhabit. Orienting oneself within the multitude of voices requires that the individual transform the voices and messages encountered in various activities, not by simply internalizing collective representations, but by reconstructing and orchestrating them in personally meaningful forms that resonate with past life experiences and with future possibilities (Skinner et al., 2001).

Educational researchers should seek a deeper understanding of dialogicality that goes beyond classroom dialogue, and even the presence of other persons in one's discourse. As Zittoun (2014) writes, "If dialogicality is a proper condition of the mind - of the person in her social and cultural environment then it is important to see what supports such dialogicality" (p. 105). In the analysis presented here I explore a variety of dialogical processes in the production of a feature story, which seem to nourish youths' capacity for reinventing themselves. Further research should continue this line of inquiry in order to provide a more nuanced understanding of dialogical processes, in order strengthen efforts to understand the conditions that sustain dialogicality and create openings for agency and the potential for dialogical action in one's community and world.

\section{Acknowledgment}

I would like to thank the reviewers, Diana Jaleh Arya, and especially Ana Marjanovic-Shane and Antti Rajala for their dialogical approach to reviewing and editing, which has been essential to bringing this manuscript to publication, while providing me with an invaluable learning experience. 


\section{References}

Bakhtin, M. M. (1981). The dialogic imagination: Four essays (C. Emerson \& M. Holquist, Trans.). Austin, TX: University of Texas Press.

Bakhtin, M. M. (1991). The Dialogic Imagination: Four essays (C. Emerson \& M. Holquist, Trans.). Austin, TX: University of Texas Press.

Bloome, D., Carter, S. P., Christian, B. M., Otto, S., \& Shuart-Faris, N. (2005). Discourse analysis and the study of classroom language and literacy events: A microethnographic perspective. Mahwah, N.J.: Lawrence Erlbaum Assoc.

Castanheira, M. L., Crawford, T., Dixon, C., \& Green, J. (2000). Interactional Ethnography: An Approach to Studying the Social Construction of Literate Practices. Linguistics and Education, 11(4), 353-400.

Cole, M. (1996). Cultural psychology: A once and future discipline. Cambridge, MA: Harvard University Press.

Freire, P. (2000/1970). Pedagogy of the oppressed. New York: Continuum.

Freire, P. (2005). Education for critical consciousness. New York: Continuum International Publishing Group.

Geertz, C. (1973/2000). The interpretation of cultures. New York: Basic Books.

Gillespie, A., \& Zittoun, T. (2013). Meaning making in motion: Bodies and minds moving through institutional and semiotic structures. Culture \& Psychology, 19(4), 518-532.

Goodman. (2003). Teaching youth media: A critical guide to literacy, video production, and social change. New York: Teachers College Press.

Green, J., \& Wallat, C. (Eds.). (1981). Ethnography and langugage in educational settings. Norwood, NJ: Ablex Publishers.

Grossen, M., \& Orvig, A. S. (2011). Dialogism and dialogicality in the study of the self. Culture and Psychology, 17(4), 491-509.

Gumperz, J., \& Hymes, D. (1972). Directions in sociolinguistics: The ethnography of communication. New York: Holt, Rinehart and Winston.

Heath, S. B. (1983). Ways with words: Language, life, and work in communities and classrooms. New York: Cambridge University Press.

Heath, S. B., \& Smyth, L. (1994). The project of learning from the inner-city youth perspective. In F. Villarruel \& R. Lerner (Eds.), Promoting community-based progams for socialization and learning. San Francisco: Jossey Bass.

Heath, S. B., \& Smyth, L. (1999). Artshow: Youth and community development. Washington D.C.: Partners for Livable Communities.

Hermans, H. J. M. (1999). Dialogical thinking and self-innovation. Culture and Psychology, 5, 67-87.

Hermans, H. J. M. (2001). The Construction of a Personal Position Repertoire: Method and Practice. Culture \& Psychology, 7(3), 323-365. doi:10.1177/1354067X0173005

Hermans, H. J. M., \& Gieser, T. (2014). Introductory chapter: History, main tenets and core concepts of dialogical self theory. In H. J. M. Hermans \& T. Gieser (Eds.), Handbook of Dialogical Self Theory (pp. 1-22). New York: Cambridge University Press.

Hermans, H. J. M., \& Hermans-Konopka, A. (2012). Dialogical self theory: Positioning and counterpositioning in global society. New York: Cambridge University Press.

Holland, D., \& Eisenhart, M. (1990). Educated in Romance: Women, achievement, and college culture. Chicago, IL: University of Chicago Press.

Holland, D., Lachicotte, W. J., Skinner, D., \& Cain, C. (1998). Identity and agency in cultural worlds. Cambridge: Harvard University Press.

Latour, B. (1996). On interobjectivity Mind, culture and activity, 3(4), 228-245.

Ligorio, M. B., \& César, M. (Eds.). (2013). Interplays between dialogical learning and dialogical self. Charlotte, NC: Information Age.

Marková, I. (2006). On the 'inner alter' in dialogue. International Journal for Dialogical Science, 1(1), 125147. 
Marková, I., Linell, P., Grossen, M., \& Salazar Orvig, A. (2007). Dialogue in focus groups: Exploring socially shared knowledge. London: Equinox.

Märtsin, M., Wagoner, B., Aveling, E., Kadianaki, I., \& Whittaker, L. (Eds.). (2011). Dialogicality in focus:: Challenges to theory, method and application. Hauppauge, NY: Nova Science Publishers.

Matusov, E., Smith, M., Soslau, E., Marjanovic-Shane, A., \& von Duyke, K. (2016). Dialogic education for and from authorial agency. Dialogic Pedagogy: An International Online Journal, 4, 162-196. doi:10.5195/dpj.2016.172

Norton, B., \& Toohey, K. (Eds.). (2004). Critical pedagogies and language learning. New York: Cambridge University Press.

Perret-Clermnot, A. N. (2004). Thinking Spaces of the Young. In A. N. Perret-Clermnot, C. Pontecorvo, L. B. Resnick, T. Zittoun, \& B. Burge (Eds.), Joining society: Social interaction and learning in adolescence and youth (pp. 3-10). New York: Cambridge Univeristy Press.

Putney, L., Green, J., Dixon, C., Durán, R., \& Yeager, B. (2000). Consequential progressions: Exploring collective-individual development in a bilingual classroom. In C. Lee \& P. Smagorinsky (Eds.), Vygotskian perspectives on literacy research (pp. 86-126). Cambridge, UK: Cambridge University Press.

Resnick, L. B., Asterhan, C., \& Clarke, S. (Eds.). (2015). Socializing Intelligence Through Academic Talk and Dialogue. Washington D.C.: American Educational Research Association.

Rochex, J. Y. (2004). La notion de rapport au savoir: convergences et débats théoriques. Pratiques Psychologiques, 10(2), 93-106. doi:10.1016/j.prps.2004.03.001

Segal, A., Pollak, I., \& Lefstein, A. (2017). Democracy, voice and dialogic pedagogy: the struggle to be heard and heeded. Language and education, 31(1), 6-25. doi:10.1080/09500782.2016.1230124

Skinner, D., Valsiner, J., \& Holland, D. (2001). Discerning the Dialogical Self: A Theoretical and Methodological Examination of a Nepali Adolescent's Narrative. Forum: qualitative social research, 2(3). Retrieved from http://www.qualitative-research.net/fqs/

Soep, E., \& Chávez, V. (2010). Drop that knowledge: Youth radio stories. Berkeley, CA: UC Press.

Souto-Manning, M., \& Smagorinsky, P. (2010). Freire, Vygotsky, and social justice theories in English education. In S. J. Miller \& D. Kirkland (Eds.), Change matters: Critical essays on moving social justice research from theory to policy (pp. 41-51). New York: Peter Lang.

Spradley, J. (1979). The ethnographic interview. New York: Harcourt Brace Jovanovich College Publishers.

StoryCenter. (2009). Story Center. Retrieved from https://www.storycenter.org/

TheNewLondonGroup. (1996). A pedagogy of multiliteracies: Designing social futures. Harvard Educational Review, 66(1), 60-92.

Valsiner, J. (2007b). Culture in minds and societies: Foundations of cultural psychology. New York: Sage Publications.

Walker, D. (2003). Constructing artistic, literate, and social identities after school: Community cultural resources in support of Latino youth. [Ph.D. Dissertation manuscript].

Walker, D. (2014). A pedagogy of powerful communication: Youth radio and radio arts in the multilingual classroom. New York: Peter Lang.

Wegerif, R. (2013). Dialogic: Education for the Internet age New York: Routledge.

Wegerif, R. (2017). Dialogic Space, and why we need it. Retrieved from http://www.rupertwegerif.name/blog/dialogic-space-why-we-need-it

YouthRadio. (2016). Youth Radio for Teachers. Retrieved from https://youthradio.org/for-teachers/

Zittoun, T. (2006). Transitions: Development through symbolic resources. Greenwich, CT: Information Age Publishing.

Zittoun, T. (2008). Learning through transitions: The role of institutions. European Joumal of Psychology of Education, 23(2), 165-181.

Zittoun, T. (2012). On the emergence of the subject. integrative Psychological and Behavioral Science, 46(3), 259-273.

Zittoun, T. (2014). Three dimensions of dialogical movement. New Ideas in Psychology, 32, 99-106.

Zittoun, T. (2017). Modalities of Generalization Through Single Case Studies. integrative Psychological and Behavioral Science, 51, 171-194. doi:10.1007/s12124-016-9367-1 
Zittoun, T., Duveen, G., Gillespie, A., Ivinson, G., \& Psaltis, C. (2003). The use of symbolic resources in developmental transitions. Culture and Psychology, 9(4), 415-448.

Zittoun, T., \& Grossen, M. (2010). L'actualisation d'intentions didactiques en classe de littérature, philosophie et culture générale: un essai d'analyse transversale. Neuchatel, Switzerland: Université de Neuchatel. Retrieved from Neuchatel, Switzerland:

Zittoun, T., \& Grossen, M. (2013). Cultural elements as means of constructing the continuity of self across various spheres of experience. In M. B. Ligorio \& M. César (Eds.), Interplays between dialogical learning and dialogical self (pp. 99-126). Charlotte, N.C.: Information Age Publishing.

\section{(cc) EY}

New articles in this journal are licensed under a Creative Commons Attribution 4.0 United States License.
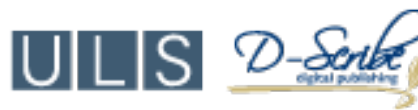

This journal is published by the University Library System, University of Pittsburgh as part of its D-Scribe Digital Publishing Program and is cosponsored by the University of Pittsburgh Press. 